\title{
TOQUE: QUAL O USO ATUAL PELO ENFERMEIRO?*
}

\author{
Magda Cristina Queiroz Dell'Acqua** \\ Vilanice Alves de Araujo*** \\ Maria Júlia Paes da Silva****
}

DELL'ACQUA, M.C.Q.; ARAUJO, V.A. de; SILVA, M.J.P. da. Toque: qual o uso atual pelo enfermeiro? Rev. Latinoam. Enfermagem, Ribeirão Preto, v. 6, n. 2, p. 17-22, abril 1998.

Este trabalho tem como objetivo verificar o uso do toque pelo enfermeiro, na categoria proposta por LE MAY (1986), assim como sua percepção de quando e por que ele o utiliza. Foram entrevistados, para tanto, 37 enfermeiros (20 docentes, 16 assistenciais e 1 aprimorando), em setembro de 1995, na capital e interior do Estado de São Paulo, constatando-se que a maioria da amostra coletada fez menção ao toque de forma expressiva, referindo utilizá-lo principalmente para demonstrar empatia e segurança em momentos que percebe a expressão das emoções do paciente.

UNITERMOS: comunicação não verbal, toque

\section{APRESENTAÇÃO}

Ao cursar a disciplina "Comunicação na Saúde do Adulto", vinculada ao programa de Pós-Graduação em enfermagem da USP, foi realizado um seminário sobre toque e, durante sua realização, sentiu-se um forte estímulo para realizar um trabalho sobre o assunto.

O tema foi estimulante não só para as autoras, como também para os demais participantes da disciplina, sendo extremamente produtivo abordá-lo, pois aproximar-se e compreender o código que rege determinado tema pode ser uma inestimável experiência.

Em discussões, notou-se que o assunto é pouco explorado nos cursos de graduação em enfermagem, sendo entretanto bem aceito quando abordado em pósgraduação. Percebeu-se também uma receptividade grande por parte das pós-graduandas em receber novos conceitos, se é que se pode chamar novo conceito o assunto em questão -"Toque"- pois vê-se o mesmo como instrumento básico indispensável para o desenvolvimento das atividades assistenciais do enfermeiro.

Com isto, fez-se um levantamento para verificar a opinião dos enfermeiros sobre o uso atual do toque por eles, e de que forma têm sido utilizado.

\section{INTRODUÇÃO}

A pele é o mais sensível e antigo de nossos órgãos, configura o primeiro meio de comunicação com o mundo, sendo através dela que o ser humano apreende o seu ambiente e percebe o mundo externo ${ }^{7}$.

$\mathrm{O}$ toque é considerado como uma das maneiras mais importantes de comunicação não verbal, podendo enviar mensagens positivas e negativas para o paciente, dependendo do momento, forma e local onde ocorre ${ }^{1}$. É proposto que se analise o toque de acordo com sua duração, localização (se ocorre em áreas mais sensíveis, mais externas ou mais próximas do coração), velocidade de aproximação do outro (abrupto ou gradual), intensidade ou a pressão exercida no outro, freqüência e sensação provocada (reação de conforto ou desconforto na pele ao receber ou transmitir o estímulo) ${ }^{10}$.

LE MAY (1986) abordando Watson, tem como definição de toque o contato físico intencional entre as pessoas, classificando-o, na área de saúde, como: a) toque instrumental: o contato físico deliberado, necessário para o desempenho de uma tarefa específica e b) toque

\footnotetext{
* Trabalho apresentado no $5^{\circ}$ SIBRACEn

** Enfermeira. Auxiliar de Ensino do Curso de Enfermagem UNESP.FMB Botucatu, Mestranda do Curso de Pós-Graduação da Escola de Enfermagem da Universidade de São Paulo. Bolsista do CNPq

*** Enfermeira. Docente do Centro de Formação e Aperfeiçoamento em Ciências da Saúde do Instituto do Coração-HC FMUSP, Mestranda do Curso de Pós-Graduação da Escola de Enfermagem da Universidade de São Paulo

**** Enfermeira. Professor Doutor do Departamento de Enfermagem Médico Cirúrgica da Escola de Enfermagem da Universidade de São Paulo
} 
expressivo: o contato relativamente espontâneo e afetivo, não obrigatoriamente relacionado a uma determinada tarefa física ${ }^{5}$.

No que diz respeito ao exercício profissional da enfermagem, o toque tanto pode ser utilizado somente como instrumental, quando se executam técnicas como sondagens, curativos e administração de medicamentos, como pode ser utilizado de maneira mais consciente, quando o toque é expressivo, para oferecer ao paciente/ cliente uma assistência embasada no objetivo de encorajálo a se comunicar e demonstrar aceitação e empatia, entre outros aspectos.

É entendida como finalidade do toque a possibilidade de usá-lo como tratamento, além de meio de comunicação e integração humana. Conforme a literatura específica sobre o assunto na área de enfermagem, GODOY afirma que são tão poucos os trabalhos sobre esse tema que poderia se dizer que ele é dispensável à ação do enfermeiro, quando na verdade, a maioria das ações de enfermagem envolvem o tocar ${ }^{4}$.

Para prestar assistência ao paciente/cliente é citada como premissa a necessidade de compreendê-lo, para assim ministrar os cuidados de enfermagem, e esta compreensão será oriunda do que for expresso por ele de maneira verbal e também do não verbal. Com isto existirá sempre comunicação, reconhecendo que até mesmo o silêncio é uma forma de se comunicar. Para tanto, o enfermeiro terá que se manter atento aos diferentes canais onde a interação está ocorrendo ${ }^{8}$.

É referida à comunicação não verbal como uma possibilidade importante do enfermeiro responder às necessidades emocionais do paciente/cliente. Completando tal idéia, a autora refere que o toque, como modalidade de comunicação, pode ser um caminho pelo qual o enfermeiro estabelece uma interação em curto período de tempo. Afirma ainda que é mais freqüente encontrar expressões faciais positivas (que demonstram alegria, satisfação, calma) em pacientes gravemente enfermos e tocados afetivamente pelo pessoal da enfermagem, do que em pacientes só tocados em momentos "técnicos", quando ocorre a execução de algum procedimento ${ }^{6}$.

Existem também alguns fatores que podem interferir na compreensão da comunicação não verbal, especificamente no que diz respeito a tocar ou não um indivíduo, devendo ser considerados a idade e o sexo dos comunicadores, aspectos culturais, diferenças individuais, pressão exercida no ato de tocar, local a ser tocado e necessidade de espaço pessoal apresentada pelo paciente ${ }^{9}$.

O ato de tocar é sempre apontado como um tipo especial de proximidade, pois quando uma pessoa toca a outra, a experiência inevitavelmente é recíproca ${ }^{3}$. Tocase para "passar" algo, mas também para "sentir" algo, desde a temperatura, forma, emoção, entre outros aspectos. Assim sendo, é ressaltada a necessidade do enfermeiro perceber o processo de comunicação, devendo validá-lo e interpretá-lo sempre no contexto em que ocorre a interação .

Como foi exposto, o toque faz parte das atividades cotidianas do enfermeiro e em algumas circunstâncias particulares, devem ser consideradas e receber atenção específica. Essas situações dizem respeito à condição de vivenciar o isolamento, a dor, a auto-estima e a auto-imagem comprometidas, o processo de morrer ou qualquer outra situação em que o paciente esteja submetido a uma dura realidade ${ }^{2}$.

É recomendado que os enfermeiros façam maior uso da possibilidade de tocar os pacientes/clientes, pois a estes profissionais já foi concedido este privilégio, pelas próprias características da profissão. Então, que isto se dê de forma consciente e intencional, estando integrado na forma de assistir ${ }^{4}$.

Deve-se ressaltar a necessidade de trazer o toque expressivo como parte da interação necessária no cuidar, considerando um anterior envolvimento entre o profissional e o paciente/cliente capaz de propiciar isto. A intencionalidade de cuidar de forma integrada, tendo claro para si mesmo que o homem é um ser indissoluvelmente possuidor de aspectos biopsicoemocionais (por que não dizer espirituais) que se interrelacionam, interfere no planejamento da assistência de enfermagem e no tempo "gasto" com o ensino desse aspecto do tocar junto a sua equipe e seus alunos.

\section{OBJETIVOS}

Diante do exposto, decidiu-se verificar como está ocorrendo o uso do toque pelos enfermeiros, atualmente. Têm-se como objetivos neste trabalho:

1. Verificar a percepção sobre o uso do toque pelo enfermeiro, segundo a classificação de toque instrumental ou expressivo;

2. Verificar quando o enfermeiro refere utilizar o toque no seu trabalho;

3. Verificar por que ele utiliza o toque, segundo sua própria percepção.

\section{MATERIAL E MÉTODO}

\section{População e local do estudo}

A população desse estudo constou de 37 enfermeiros, sendo 36 do sexo feminino e 1 do sexo masculino. A idade dos enfermeiros variou de: $4(10,8 \%)$ 
com mais de 40 anos; 8 (21,6\%) enfermeiros de 35-40 anos; $16(43,2 \%)$ de 30-35 anos; $6(16,2 \%)$ enfermeiros de 25-30 anos; 2 (5,4\%) enfermeiros de 20-25 anos e 1 omitiu esse dado.

O tempo de formado de $18(48,6 \%)$ enfermeiros era de mais de 10 anos; estando os demais distribuídos em 17 (45,9\%) com tempo de 4-10 anos; 1 (2,7\%) com tempo de 2-4 anos e 1 com tempo de 0-2 anos. Vinte (54\%) desses enfermeiros exercem função docente, 16 $(43,2 \%)$ função assistencial e um 1 está fazendo um curso de aprimoramento.

Quanto à caraterística das instituições de trabalho, $24(64,8 \%)$ dos enfermeiros atuam em instituições públicas; $8(21,6 \%)$ em instituições mistas e $5(13,5 \%)$ em instituições particulares.

\section{Procedimento}

Para coleta de dados foi utilizada a entrevista estruturada, com um roteiro constituído de 2 partes. A primeira contendo dados de identificação: tempo de formado, função que exerce, idade, sexo, área de atuação, instituição em que atua; com o objetivo de verificar se estas variáveis interferiram nas respostas do uso do toque pelos enfermeiro, segundo a classificação de LE MAY (1986 ). A segunda parte conteve 3 perguntas abertas: o que é tocar o paciente?, quando e por que utiliza o toque para se obter dados relativos ao uso deste para o enfermeiro?.

O instrumento utizado para coleta dos dados, antes de ser aplicado aos sujeitos participantes do estudo, foi validado por três professoras, estudiosas de comunicação.

Esta entrevista foi aplicada, no mês de setembro de 1995 na capital e em uma cidade de porte médio do interior de São Paulo, aos enfermeiros assistencias e docentes, 1 aprimorando e alunos de cursos de pósgraduação do mestrado e doutorado, provenientes de diferentes instituições e estados.

Após expor os objetivos da pesquisa e obter a autorização verbal dos enfermeiros em participar, estes foram entrevistados pelas pesquisadoras, que apresentavam o roteiro e conforme as respostas eram pronunciadas as anotações eram realizadas concomitantemente.

Pelas respostas obtidas, pôde-se classificá-las de acordo com a definição feita por LE MAY (1986) que definiu o toque em duas categorias, como instrumental e expressivo 5 .

\section{APRESENTAÇÃO DOS RESULTADOS}

As respostas referentes à parte II do instrumento de coleta de dados, relativas ao uso do toque pelos enfermeiros, é apresentada na seqüência das perguntas feitas.

Cabe ressaltar que o número das respostas apresentadas, nos quadros a seguir, não corresponde ao total de enfermeiros (37), pois houve narrativas que continham as duas denominações em partes distintas.

Pelo Quadro 1, pode-se perceber o que é o toque para os enfermeiros pesquisados, já de acordo com a classificação de LE MAY (1986).

QUADRO l - O que é para você tocar o paciente? São Paulo, 1995

\begin{tabular}{|lc|}
\hline \multicolumn{1}{|c|}{ CATEGORIA } & NÚMERO \\
\hline Toque Expressivo & 32 \\
Toque Instrumental & 13 \\
Não se enquadra & 1 \\
\hline
\end{tabular}

No Quadro 1 observa-se que $32(69,5 \%)$ das citações dizem respeito ao tocar de forma expressiva, ou seja, o toque que ocorre com um grau de espontaneidade, entendendo que o enfermeiro também faz parte deste processo de comunicação não verbal, pois o ato de tocar é bilateral, havendo uma exposição do profissional que proporciona a troca ${ }^{9}$. Algumas citações como "...mostrar interesse e com isso interagir com o doente...", “...quebrar barreiras, estabelecer um canal...", “...fazer-se presente...", “...transmitir carinho...pode contar comigo..."; fizeram parte das respostas dos enfermeiros.

Obteve-se também $13(35,1 \%)$ citações referentes ao toque instrumental, causando surpresa às autoras que, pela experiência profissional e através de leitura de outros estudos, esperavam um número maior nesta categoria. Esses enfermeiros justificaram o uso para eles citando que o toque é para "...fazer uma técnica...", “...detectar alterações físicas...”, “...um meio de auxílio na movimentação...", etc.

Em pesquisa recente, de observação feita por alunos de graduação, em diferentes hospitais, verificouse que a maioria das vezes o enfermeiro toca o paciente para a execução do exame físico, ou seja, executa um toque instrumental ${ }^{9}$. Porém, pudemos perceber, por este levantamento, que, conceitualmente, os enfermeiros se referem ao toque de maneira expressiva.

Como já foi dito, este quadro revelou que esta determinada amostra demonstra que o toque significa mais do que um simples instrumento para a realização das atividades, revela-se, portanto, expressivo quando espontâneo, sendo um elemento importante de interação humana no cuidar dos pacientes ${ }^{4}$. 
Cabe ressaltar que as variáveis "tempo de formado", "função que exerce", "idade", "sexo", "área de atuação" ou "instituição em que atua", não interferiram nos resultados encontrados, segundo a classificação de LE MAY ${ }^{5}$.

No Quadro 2 observa-se o número de respostas encontradas com a pergunta "quando você utiliza o toque"?, já classificadas na proposta de LE MAY (1986), quanto ao tipo de toque.

QUADRO 2 - Categorias do toque, segundo o relato dos momentos em que o enfermeiro toca o paciente. São Paulo, 1995

\begin{tabular}{|lc|}
\hline CATEGORIA & NÚMERO \\
\hline Toque Expressivo & 30 \\
Toque Instrumental & 16 \\
Não se enquadra & 1 \\
\hline
\end{tabular}

No Quadro 2 manteve-se ainda o toque expressivo com a maioria das citações dos enfermeiros: $30(65.2 \%)$ vezes, enquanto o toque instrumental apareceu com 16 (34,7\%) citações, situações que se percebeu o momento de seu uso. As respostas relativas a quando utilizam o toque foram, assim, classificadas como expressivo através das expressões: “...quando o percebo tenso...”, “...deprimido...”, “...quando preciso ajudá-lo para se sentir melhor...”. Dentre as respostas classificadas como instrumentais, algumas foram assim expressadas: “...banho, injeção...”, “...exame físico...”, “...quando faço técnicas...”.

É interessante ressaltar, que, a maioria da amostra pesquisada (20) foi composta de docentes da enfermagem, que na realidade, não mantêm o contato diário com o paciente e, muitas vezes, acompanham o aluno na execução das técnicas de enfermagem, mas não as executa.

As respostas que demonstram a utilização do toque de forma expressiva, estão relacionadas a momentos de percepção das emoções dos pacientes por parte dos enfermeiros. A bibliografia reforça a importância do toque nesses momentos, lembrando que ele realmente pode transmitir confiança, apoio e atenção, desde que o enfermeiro utilize o "bom senso" e não se esqueça do estilo de vida e cultura de cada paciente ${ }^{2,4,9}$.

A classificação das respostas à pergunta sobre o por que o enfermeiro utiliza o toque, pode ser vista no Quadro 3, a seguir.
QUADRO 3 - Categorias do toque segundo o relato das justificativas do porquê o enfermeiro toca o paciente. São Paulo, 1995

\begin{tabular}{|lc|}
\hline \multicolumn{1}{|c|}{ CATEGORIA } & NÚMERO \\
\hline Toque Expressivo & 32 \\
Toque Instrumental & 10 \\
Não se enquadra & 1 \\
\hline
\end{tabular}

No Quadro 3 pode-se verificar a razão da utilização do toque para os enfermeiros, observando-se que a maioria das respostas ainda se mantém na classificação de toque expressivo: $32(74,4 \%)$ e apenas $10(23,2 \%)$ citações referem-se ao toque instrumental. As narrativas demonstram que os enfermeiros questionados foram coerentes nas respostas colocando que tocar "...é a única maneira de se fazer presente...", "...transmitir segurança...", “...substituir muitas palavras...", e que a minoria relatou perceber o toque como "...instrumento de trabalho...", “...para executar a prática...", “...evoluir uma ferida...”.

Verifica-se, pelas narrativas, que a maioria dos enfermeiros referiu-se ao toque afetivo, como realmente o tipo de toque em que se permite escolher o momento e o local para torná-lo terapêutico, positivo. Visto que um dos fatores de análise do tocar se refere à pressão exercida, não podemos esquecer que na própria execução de um procedimento, também passamos o que estamos sentindo, ou o valor que damos ao trabalho executado, pela maneira como o paciente percebe esse toque e pelos demais sinais não verbais presentes na situação de interação (a expressão facial do enfermeiro, sua postura corporal; a forma como se aproximar do paciente, entre outros) ${ }^{10}$.

\section{CONSIDERAÇÕES FINAIS}

Com base nos dados obtidos nesse trabalho, podese considerar que os enfermeiros, quando questionados, deram maior ênfase ao uso do toque expressivo, embora também, na compreensão de alguns, o toque instrumental foi a única escolha.

As autoras consideram que as respostas foram coerentes, pois os resultados demonstraram uma compreensão de toque para os enfermeiros, voltada para o expressivo nas 3 questões formuladas; as situações citadas nas perguntas dois e três (quando e por que utilizam o toque) mantiveram-se coerentes com as respostas da primeira questão: toque é "...quebrar barreira...", “...estabelecer um canal”, "transmitir carinho...". De acordo com a maior parte das bibliografias 
utilizadas, têm-se ainda resultados pouco significativos no que tange à utilização do toque afetivo da enfermeira em relação ao cuidar do paciente/cliente. Neste estudo, os enfermeiros consultados demonstraram o inverso, dando ênfase à importância do toque espontâneo com o objetivo de ajudar e interagir.

Como não era o objetivo do estudo verificar como esses mesmos enfermeiros atuavam realmente junto aos pacientes, ficou claro que, conceitualmente, a amostra tem consciência da importância do toque afetivo nos cuidados em enfermagem. Consideramos importante e interessante a realização de outros estudos, verificando se a prática profissional está coerente ao discurso teórico apresentado, visto a divergência dos estudos existentes.

\section{TOUCH: WHAT IS ITS ACTUAL USE BY NURSES?}

This study aims to verify the use of the touch by nurses according to LE MAY'S proposal (1986), as well as to verify when and why he uses it, according to his own perception. Thirty-seven nurses (20 teachers, 16 assistants and 01 who was attending a specialization course) were interviewed in September 1995 in the capital and other cities of the State of São Paulo, showing that the majority of the collected samples mentioned touch in an expressive manner, referring to using it mainly to demonstrate empathies and security on moments where patient's emotion were perceived.

KEY WORDS: nonverbal communication, touch

\section{TOQUE: CUÁL EL USO ACTUAL PARA EL ENFERMERO?}

Este trabajo tiene como objetivo verificar el uso del toque para el enfermero, según la propuesta de LE MAY (1986), asi como analizar cuando y porqué se utiliza según su percepción. Fueron entrevistados 37 enfermeros (20 profesores, 16 asistenciales y uno preparandose para una especialidad). En Septiembre de 1995, en la capital y en los pueblos del estado de São Paulo se constató, que la mayoría de los entrevistados hicieron referencia al toque de una forma expresiva y citaron utilizarlo, principalmente en momentos que perciben las emociones del paciente y para poder demostrar afectividad y seguridad.

TÉRMINOS CLAVES: comunicación no verbal, toque

ANEXO - TOQUE

\section{I - IDENTIFICAÇÃO}

1. Tempo de formado:

2. Função que exerce:

3. Idade:

4. Sexo:

5. Área de Atuação:

6. Instituição em que atua:

\section{II - TOQUE}

7. O que é para você tocar o paciente?

8. Quando você utiliza o toque?

9. Por que você utiliza o toque? 


\section{REFERÊNCIAS BIBLIOGRÁFICAS}

01. BLONDIS, M.N.; JACKSON, B.E. Nonverval communication with patients: back to human touch. 2.ed. New York: John Wiley, 1982. cap 1. p. 2-29: What is nonverbal communication?

02. BRADY, B.A. Using the right touch. Nursing, v.21, n.5, p.46-7,1991.

03. DAVIS, F. Comunicação não verbal. São Paulo: Summus, 1979.

04. GODOY, A.N. de. O toque como elemento de integração na relação enfermeiro-cliente. Rev.Gaúch. Enfermagem., v.6, n.2, p.305-16, 1985.

05. LE MAY, A. Therapeutic touch: the human connection. Nurs.Times, v.82, n.47, p.28-30, 1986.
06. MC CORKLE, R. Effects of touch on seriously ill patients. Nurs. Res., v.23, n.2, p.125-32, 1974.

07. MONTAGU, A. Tocar: o significado humano da pele. São Paulo: Summus, 1988.

08. SILVA, M.J.P.da. O toque e a distância interpessoal entre enfermeiros e pacientes nas consultas de enfermagem. Rev. Esc. Enfermagem USP, v.25, n.3, p.309-18, 1991.

09. SILVA, M.J.P. da; STEFANELLI, M.C. Percepções sobre o toque enfermeira e paciente: visão dos alunos de graduação. Rev. Esc. Enfermagem USP, v.28, n.3, p.270-80, 1994.

10. WEISS, S.J. The language of touch. Nurs.Res., v.28, n.2, p.76-80, 1979. 